\title{
Removal of ammonia from leachate by using thermophilic microbial fuel cells equipped with membrane electrode
}

\author{
Kuo-Ti Chen ${ }^{1,2}$, Min-Der Bai', Hui-Yun Yang ${ }^{1}$, Yu-Ching Chen ${ }^{1}$, Wen-Jang Lu ${ }^{1}$ and Chihpin Huang ${ }^{2 *}$
}

\begin{abstract}
In wastewater treatment, biological nitrogen removal is an important topic, and the optimal condition for it is a mesophilic environment. This study developed a thermophilic microbial fuel cells (thermo-MFCs) equipped with a hydrophobic membrane electrode to remove and recover ammonia and water from leachate. The results were compared with those of the mesophilic MFCs (meso-MFCs) and they show that the current and power densities for meso-MFCs are higher. The ammonia removal efficiencies of thermo-MFCs are 83\% (closed circuit) and 60\% (open circuit), higher than those of closed- and open-circuit meso-MFCs (48 and 38\%, respectively). Water vapor, the main recovery water flux for the thermo-MFCs, provided $36.5 \mathrm{~L} \mathrm{~m}^{-2} \mathrm{~d}^{-1}$ using the closed-circuit mode without applied energy. Moreover, thermo-MFCs and meso-MFCs can be restored within $24 \mathrm{~h}$ even under inhibition by using 7200 $\mathrm{mg} \mathrm{L}^{-1}$ ammonia. The proposed process presents an economic and ecofriendly method to not only recover water and ammonia from leachate but also alleviate ammonia inhibition.
\end{abstract}

Keywords: Microbial fuel cells, Renewable energy, Ammonia inhibition, Water recovery

\section{Introduction}

Wastewater treatment, combined with energy, nutrition, and water recovery, is an emerging strategy to address sustainable development issues. However, the high operational cost and complex process impede practical application. During an anaerobic operation, biological degradation of nitrogenous matter leads to ammonia production. Unionized ammonia is significantly more toxic than is the ammonium ion because ammonia can enter cells, disturb the proton equilibrium, and/or interfere with the metabolic enzymes [1]. However, ammonium is a valuable fertilizer in agriculture and promotes eutrophication in water bodies. Thus, ammonia removal and recovery are essential in wastewater treatment and resource recovery.

Many methods have been developed for ammonia removal like nitrification-denitrification and recovery such as gas stripping and absorption, chemical precipitation (struvite), and hydrophobic membrane separation and absorption; however, all of them have several limitations.

\footnotetext{
* Correspondence: cphuang@mail.nctu.edu.tw

${ }^{2}$ Institute of Environmental Engineering, National Chiao Tung University, Hsinchu 30010, Taiwan

Full list of author information is available at the end of the article
}

For instance, nitrification-denitrification is a complex process that is only suitable for low nitrogen concentrations, requires considerable energy, and uses organic carbon sources. In addition, the optimal temperature for biological nitrogen removal is $35^{\circ} \mathrm{C}$ [2]. Therefore, it needs heat exchangers or cooling towers to lower the temperature of the thermophilic wastewater before treatment. To increase the volatile ammonia percentage and removal rate, both ammonia stripping and the hydrophobic membrane separation are energy-intensive processes and require large amounts of $\mathrm{NaOH}$ to increase the temperature and $\mathrm{pH}$ of the medium. Struvite crystallization has gained interest as a method for phosphorus and nitrogen recovery [3]. Directly formed struvite crystals in wastewater systems are likely to contain crystals other than struvite because of ionic interactions, $\mathrm{pH}$ changes, temperature effects, and ion clustering during nucleation and crystal growth [4], which deteriorates the struvite quality.

A microbial fuel cell (MFC) can oxidize an organic substrate into $\mathrm{CO}_{2}$, proton, and electron with the electron transfers from an external circuit from the anode to the cathode, in addition to inducing charge transfer (i.e., cation or anion migration) in the electrolyte. The ammonium ion migrates to the cathode in the electric field 
while the oxygen reduction reaction occurs and produces hydroxides, leading to a higher $\mathrm{pH}$ adjacent to the cathode. In a high $\mathrm{pH}$ environment, the ammonium ion converts to volatile ammonia and diffuses from the membrane because of the concentration difference. On the basis of this ammonium ion migration and electrochemical reaction, Kuntke et al. [5] used a singlechamber air-cathode MFC to demonstrate that the volatile ammonia diffuses through the membrane electrode, indicating that an MFC can be used to recover ammonium and to produce energy [6].

The single-chamber air-cathode membrane-less configuration can reduce the MFC construction cost. It exhibits high power density because of its low resistance, but the coulombic efficiency is low because of oxygen intrusion. In addition, water loss from the air cathode is its main disadvantage [7]. However, the vapor diffuses through the membrane can be collected as recovery water during the wastewater treatment process.

The thermophilic anaerobic treatment process is highly efficient and eliminates most pathogens, and thus, it is preferred in wastewater treatment process and bioenergy production. However, it is unstable, particularly for nitrogen inhibition at high temperature. There have been many studies on nitrogen recovery using an MFC $[5,6,8]$ and membrane separation $[9,10]$; however, most of them were conducted in an ambient or mesophilic environment. Thus, the aim of this study is to evaluate the following for thermophilic single-chamber air-cathode MFCs in open circuit (i.e., without electrochemical reaction) or closed circuit (i.e., with electrochemical reaction) modes: performance of the MFCs, ammonia removal efficiencies, flux and quality of the recovery water, quality of the collected struvite, and the restoration activity from the inhibition caused by high-strength ammonia wastewater. In addition, all results are compared with the operation of a mesophilic MFC (meso-MFC).

\section{Materials and methods MFC and operation}

In this study, single-chamber air-cathode membrane-less MFCs were used for the treatment of leachate from the thermophilic solid-state anaerobic digestion of chicken manure. A net volume of $130 \mathrm{~mL}$ of MFC was formed in a 100$\mathrm{mL}$ serum bottle with a $20-\mathrm{mm}$ inside diameter glass tube with flanges at the lower end. The cathode was set between the flanges, one side of the cathode exposed to the air and the pipe cross-sectional area is $3.14{ }^{*} 10^{-4} \mathrm{~m}^{2}$ as the cathode area.

A schematic of the MFC with a water and ammonia recovery system is presented in Fig. 1. A carbon brush (pmbiz.com.cn) refined to $5 \mathrm{~cm}$ diameter and $6 \mathrm{~cm}$ length was used as the anode. A carbon paper (GDL 240, CeTech, Taiwan), with a microporous layer and PTFE (polytetrafluoroethene) without a precious metal catalyst was used as the cathode. The carbon paper had an air permeability of $<85 \mathrm{~s}$ by Gurley airflow test method and was conductive, hydrophobic, and air permeable. The compressed air was passed through a desiccant at $110 \mathrm{~mL} \mathrm{~min}^{-1}$ as a sweeping gas. The air stream removed water vapor and volatile ammonia from the surface of the cathodic membrane electrode, and it supplied oxygen for the cathode reduction reaction. The air stream containing water vapor passed through a $6^{\circ} \mathrm{C}$ glass condenser tube that collected the condensate as recovery water. The air stream with volatile ammonia was absorbed into diluted phosphoric acid. The MFC reactor was weighed during its operation every day, the new weight was compared with the initial weight to determine the water loss from the cathode membrane. The water flux was calculated by dividing the water loss and membrane area as $\mathrm{L} \mathrm{m}^{-2} \mathrm{~d}^{-1}$. After that, the deionized water was added using a syringe to compensate for the MFC water loss, which prevented ion concentration during the experiment.

A mixture of thermophilic solid-state anaerobic fermentation leachate and mesophilic anaerobic wastewater (mixing ratio 1:1) from chicken manure treatment plant was used to inoculate the MFC anode. The $20 \%$ volume of inoculum was mixed with the sterilized M9 medium ( $10 \mathrm{mM}$ of sodium acetate as carbon sources) was used as the bioanode culture medium. A $200 \Omega$ resistor was connected between the anode and the cathode. After putting the anode into MFC, moved the MFC into thermophilic or mesophilic temperature control chamber to culture. The deionized water was added daily to make up the water loss from the MFC. As the voltage dropped to $10 \mathrm{mV}$, additional sodium acetate (around $10 \mathrm{mM}$ ) was added to the anode chamber. After more than $30 \mathrm{~d}$ of culture, both meso-MFC and thermo-MFC produced a stable current. The bioanode has been cultured and proceed the following experiment.

The leachate came from our $10 \mathrm{~m}^{3}$ thermophilic solidstate anaerobic fermentation of chicken manure. The sample was sealed tightly and kept in a cooler and stored in a $4{ }^{\circ} \mathrm{C}$ refrigerator until it was used. The leachate was collected at two different periods. The first one (leachate A) was taken at the 7th day under a stable operation, the leachate A was used directly for inoculant or the leachate was diluted for the ammonia removal experiment, the leachate for ammonia removal experiment contained 7.62$\mathrm{pH}, 14,900 \pm 150 \mathrm{mg} \mathrm{L}^{-1}$ of COD (chemical oxygen demand) and $2000 \pm 75 \mathrm{mg} \mathrm{L}^{-1}$ of ammonia $\left(\mathrm{NH}_{3}-\mathrm{N}\right)$. While the second leachate (B) came from the 3rd day operation, it was used directly without dilution and the leachate B contains high concentration of ammonia, COD, volatile fatty acid had a pH of 6.5 and contained $36,700 \pm 600 \mathrm{mg} \mathrm{L}^{-1}$ of COD and $7200 \pm 100 \mathrm{mg} \mathrm{L}^{-1}$ ammonia.

The MFC was filled with $120 \mathrm{~mL}$ of the medium, and the bioelectrode was inserted into the MFC in the 


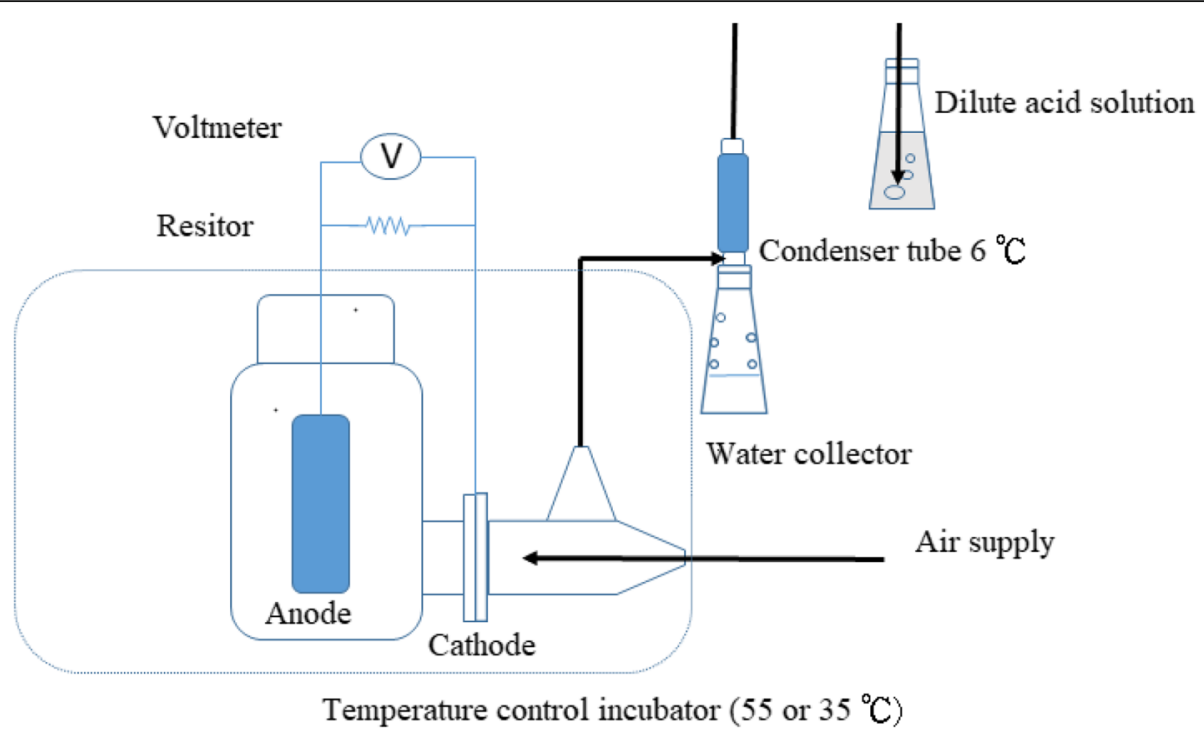

Fig. 1 Schematic of the experiment using single-chamber air-cathode MFC, the ammonia and water recovery system

laminar airflow bench. It was purged with $\mathrm{N}_{2}$ gas for 15 min to remove residual oxygen from the MFC. Next, the cap was closed and the MFC was placed in a constanttemperature orbital shaking incubator set at $35^{\circ} \mathrm{C}$ for mesophilic and $55^{\circ} \mathrm{C}$ for thermophilic environment at a speed of $20 \mathrm{rpm}$.

The cathode and anode did not connect at open circuit MFC system. The electron cannot transfer from anode to membrane cathode electrode; no electric field and electrochemical reaction at this system. While at the close circuit system, a $200 \Omega$ resistor was connected between the anode and the cathode. The MFC was operated in both modes at least two times.

\section{Chemical and electrochemical analysis}

Ammonia and COD concentrations of the medium in the MFC were measured using $\mathrm{HACH}$ Cat. 2,606,945 (ammonia) and Cat. 2,125,925 (COD) vials following the corresponding procedures. All samples were analyzed twice after being treated with a $0.45 \mu \mathrm{m}$ nylon syringe filter (Kolosh Instruments PTFE/Nylon Syringe Filter). The ammonia recovery efficiency in this test was calculated by dividing the sum of mass of ammonia absorbed in the condensed water and that of the diluted acid solution by ammonia mass loss in MFC.

The voltage was recorded every $10 \mathrm{~min}$ by using Voltage Recorder VR-71 (T\&D Corporation, Japan). The current was calculated as follows: $I=V /(R * A)$, where $I$ is the current $\left(\mathrm{A} \mathrm{m}^{-2}\right), \mathrm{V}$ the voltage $(\mathrm{V}), \mathrm{R}$ the resistance $(\mathrm{ohm})$, and $A$ the cathode area $\left(\mathrm{m}^{2}\right)$. The power was calculated as $\mathrm{P}=\mathrm{IV}$, where $\mathrm{P}$ is measured in $\mathrm{W} \mathrm{m}^{-2}$. A VSP potentiostat (BioLogic USA, Knoxville, TN, USA) was used to obtain the polarization curve and power density by using the twoelectrode method. The anode was connected to the working electrode, the counter and reference electrodes were connected to the cathode, and the scan speed was 1 $\mathrm{mV} \mathrm{s}^{-1}$ from 0.8 to $0 \mathrm{~V}$. It was conducted at the 4 th day of operation, the test was in progress and the system current production reached the plateau.

\section{Struvite recovery and analysis}

Struvite was prepared using the ammonia absorbed in diluted phosphoric acid. The mass of the collected ammonia in dilute phosphoric acid was measured, and the same molar quantity of magnesium chloride was added and mixed well. The $\mathrm{pH}$ was adjusted to approximately 10 , the solution was gently stirred for approximately $30 \mathrm{~min}$ and held for precipitation for $3 \mathrm{~h}$. Then, it was filtered using a $0.45-\mu \mathrm{m}$ filter and dried. The dry struvite was examined by X-ray diffraction (XRD) and the position and intensity of the peaks was compared with those of pure struvite. The X-ray diffractometer Bruker D2-phaser was used and operated according to its operation procedure.

\section{Results}

Current and power density of thermo-MFC and meso-MFC In this study, diluted leachate was fed into a single-chamber air-cathode membrane-less MFC. Exoelectrogenic bacteria oxidized the organic material and produced current in the closed-circuit MFC. The current densities for both mesoMFC and thermo-MFC are presented in Fig. 2a. The current density of the meso-MFC immediately reached 780 $\mathrm{mA} \mathrm{m}^{-2}$ (based on the cathode area), and gradually increased to plateau at $1900 \mathrm{~mA} \mathrm{~m}^{-2}$ after $48 \mathrm{~h}$. The thermoMFC operated with a time lag of approximately $24 \mathrm{~h}$, and the current density gradually increased to $875 \mathrm{~mA} \mathrm{~m}^{-2}$ after $60 \mathrm{~h}$ of acclimation. Dessi et al. [11] compared the microbial communities of meso- and thermo-MFC and 

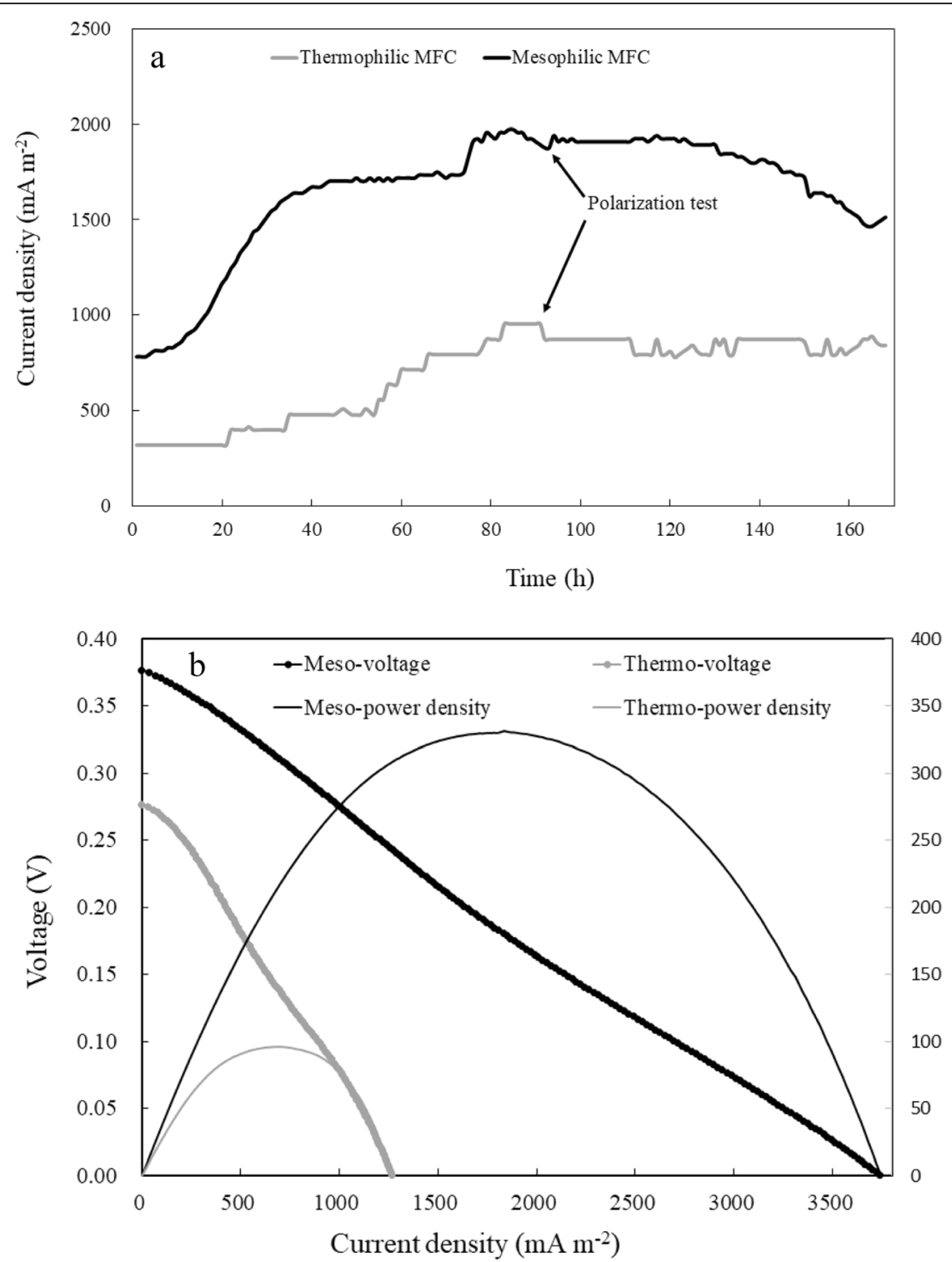

Fig. 2 The current density of the two systems and the time that polarization curve was measured (a). The meso-MFC immediately reaches 780 $\mathrm{mA} \mathrm{m}^{-2}$ (based on the cathode area), and gradually increases to plateau at $1900 \mathrm{~mA} \mathrm{~m}^{-2}$; the current density of the thermo-MFC gradually increases to $875 \mathrm{~mA} \mathrm{~m}^{-2}$. The polarization and power density of the two systems $(\mathbf{b})$. The highest voltage is $0.38 \mathrm{~V}$ for the meso-MFC and $0.28 \mathrm{~V}$ for the thermo-MFC. The highest power densities for the meso-MFC and thermo-MFC are 330 and $105 \mathrm{~mA} \mathrm{~m}^{-2}$

concluded that the Geobacter is the most significant exoelectrogens in meso-MFC whether at different inoculum or medium. But the Firmicutes are the most significant exoelectrogens at thermo-MFC. They concluded that the higher current density is attributed by the Geobacter. In this study, the thermo-MFCs exhibited a lower current density than meso-MFCs did, which may be attributed to the lack of active exoelectrogens (Geobacter), the competition of nonexoelectrogens for electrons, and the high resistance in thermo-MFCs [12].
The power density and polarization curve of mesoMFC and thermo-MFC are presented in Fig. 2b. The highest voltage was $0.38 \mathrm{~V}$ for the meso-MFC and $0.28 \mathrm{~V}$ for the thermo-MFC. The meso-MFC has the optimal temperature for exoelectrogenic bacteria, which explains the higher voltage for the meso-MFC. Power was calculated as $\mathrm{P}=\mathrm{IV}$; therefore, high current and voltage resulted in high power. As shown in Fig. 2b, the highest power densities for the meso-MFC and thermo-MFC (based on the cathode 
area) were 330 and $105 \mathrm{~mW} \mathrm{~m}^{-2}$, respectively. The current and power density for the meso-MFC were higher than those for the thermo-MFC.

\section{Ammonia removal in thermo-MFC and meso-MFC}

In this study, the leachate from the thermophilic solidstate anaerobic digestion of chicken manure with high COD and ammonia content was diluted and used. Figure 3 shows the ammonia removal efficiencies of the thermo-MFC and meso-MFC obtained in this study. Original ammonia concentration was $2000 \pm 75 \mathrm{mg} \mathrm{L}^{-1}$, and after $7 \mathrm{~d}$ of operation, the ammonia concentration (removal efficiency) for closed- and open-circuit thermoMFCs was $350 \pm 17 \mathrm{mg} \mathrm{L}^{-1}$ (83\%) and $800 \pm 38 \mathrm{mg} \mathrm{L}^{-1}$ (60\%), respectively. The ammonia concentration, removal efficiency for closed- and open-circuit meso-MFC were $1050 \pm 51 \mathrm{mg} \mathrm{L}^{-1}, 48 \%$ and $1250 \pm 45 \mathrm{mg} \mathrm{L}^{-1}, 38 \%$, respectively. The unionized $\mathrm{NH}_{3}$ increases with high temperature, irrespective of whether the MFCs operated in open- or closed-circuit modes, ammonia removal efficiency in the thermo-MFCs was higher than that in the meso-MFCs.

When the electric circuit is connected, the microorganisms catalyze the oxidation of the organic material, relieve the electrons to the anode, and the electrons flow through the external circuit to the cathode. $\mathrm{NH}_{4}{ }^{+}$is driven to migrate to the cathode by the electric field; the oxygen reduction reaction occurs at the cathode and produces hydroxyl ions, which results in an alkaline environment adjacent to the cathode surface [5]. For the closed-circuit MFC with ammonium migration and high $\mathrm{pH}$ because of oxygen reduction reaction at the cathode, a higher ammonia removal than that in the open-circuit MFC is obtained for both meso-MFC and thermo-MFC.

In this study, volatile ammonia was swept from the membrane electrode and absorbed in the condensed water and diluted acid solution, and the total ammonia recovery ratio was in the range $60-70 \%$ because of the air carryover loss and microorganism metabolism. Figure $4 \mathrm{~b}$ indicates that the XRD pattern position and intensity of the peaks generated from the struvite crystals match the reference values of pure struvite. The collected struvite in this study, presented in white, is comparable with pure struvite. This indicated that high-quality struvite can be formed using the method proposed here.

\section{COD removal in thermo-MFC and meso-MFC}

Figure 4 shows the COD removal of closed-circuit thermoMFCs, open-circuit thermo-MFCs, closed-circuit mesoMFCs, and open-circuit meso-MFCs, and their values are $59,52,27$, and $23 \%$, respectively. High temperature promotes better performance in the biological treatment process. Furthermore, when the MFC operates in the closed-circuit mode, the current production indicates that exoelectrogens are activated in the MFC system. The exoelectrogens act as catalysts for the oxidation of soluble acids, which can promote organic waste decomposition. In the open-circuit mode, the electron transfer is cut off and the activity of exoelectrogens is inhibited, because it cannot promote the decomposition of organic waste, resulting in a lower COD removal. Furthermore, high temperature promotes enhanced performance in the biological treatment process.

\section{Flux and quality of recovery water}

In this study, we used a carbon paper membrane electrode that has a microporous layer, is hydrophobic, and exhibits electrochemical activity when operated in the closed-circuit mode. Figure 5 shows the operational daily and accumulated water flux from the thermo-MFC and meso-MFC in the open- or closed-circuit modes. The average water flux values for the thermo-MFCs in closed- and open-circuit modes were 36.5 and $31.1 \mathrm{~L} \mathrm{~m}^{-}$ ${ }^{2} \mathrm{~d}^{-1}$, respectively, which are higher than those for the meso-MFCs in the closed- and open-circuit modes (16.2 and $6.3 \mathrm{~L} \mathrm{~m}^{-2} \mathrm{~d}^{-1}$, respectively). Kim et al. [13] tested the anaerobic membrane bioreactor (anMBR), the membrane flux obtained was $240 \mathrm{~L} \mathrm{~m}^{-2} \mathrm{~d}^{-1}$ with power consumption of $0.028 \mathrm{kWh} \mathrm{m}^{-3}$ [13]. In this study, although the flux is lower than that of anMBR, the condensed water does not require additional applied energy. In the open-circuit mode, because of no electrochemical reaction, the water flux through the membrane cathode increased from 6.3 to $31.1 \mathrm{~L} \mathrm{~m}^{-2} \mathrm{~d}^{-1}$ when the temperature increased from 35 to $55^{\circ} \mathrm{C}$, which can be attributed to faster evaporation at higher temperature [14]. Previous studies have indicated that when external resistance was low, more coulomb force was produced and more water was lost in the MFC, and thus, they suggested that the major water transport phenomena are related to the electro-osmotic drag in the membrane [15, 16]. The water flux in the open-circuit mode is a result of natural evaporation, but that in the closed-circuit mode is a result of natural evaporation and the electrochemical reaction. In this study, the water flux ratio for the open circuit to closed circuit was 39\%, which implies that the major water flux is related to the electroosmotic drag force when the MFC operates in a closedcircuit mesophilic environment, the results are consistent with those of Gajda et al. [17]. However, the water flux ratio for the open circuit to closed circuit was $85 \%$ for the thermo-MFC, which implies that pressure differential and natural evaporation are the main water flux in thermo-MFCs. This shows that the major water flux mode is different for meso-MFC and thermo-MFC.

Water vapor was condensed in a $6^{\circ} \mathrm{C}$ condenser for recovery, but the lower temperature also increased the solubility of volatile ammonia. In this study, the ammonia content in the recovery water was found to be $172-230 \mathrm{mg}$ $\mathrm{L}^{-1}$. Although the particulate matter in the medium was 

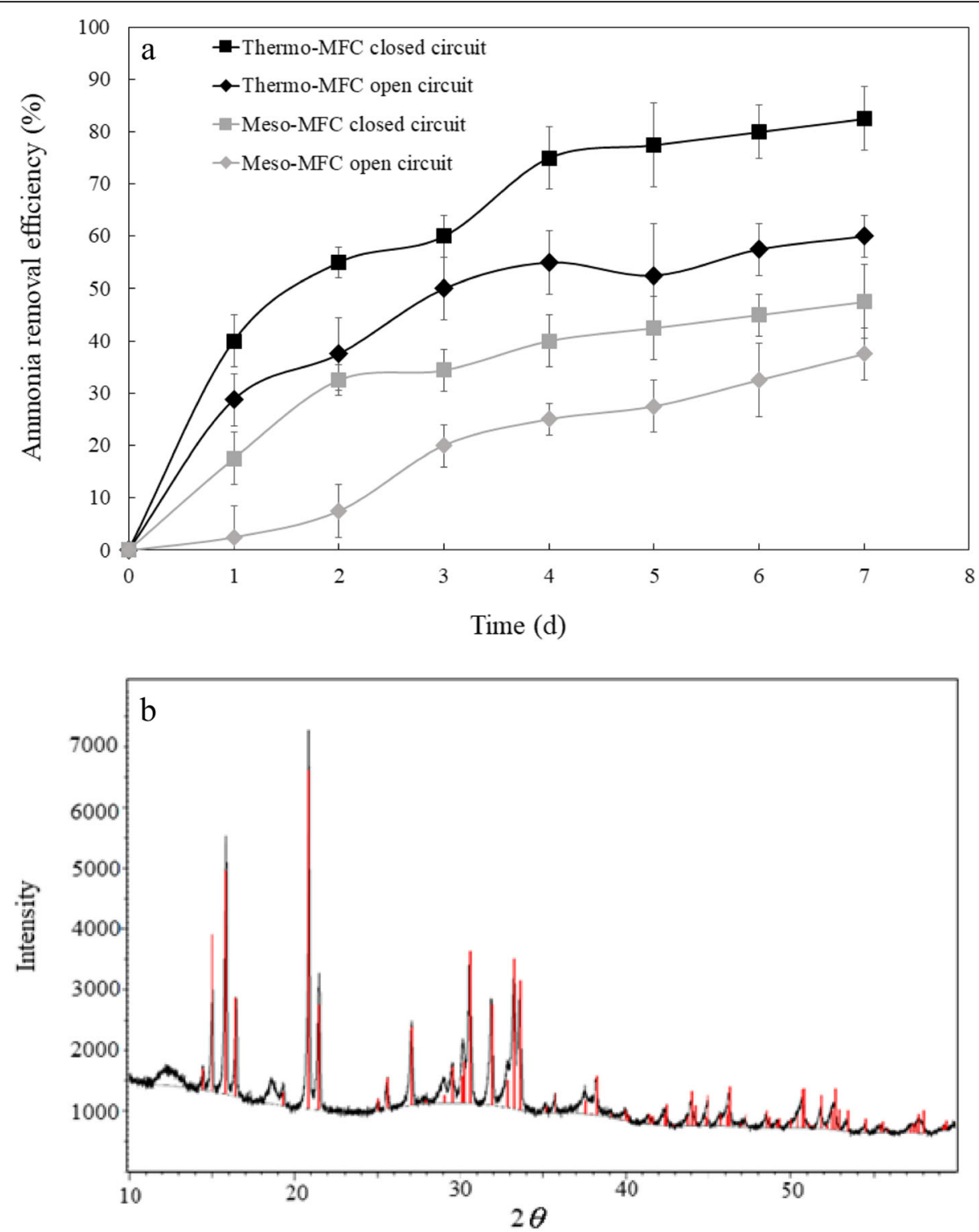

Fig. 3 Ammonia removal using thermo- and meso-MFC for open- or closed-circuit modes (bars indicate standard deviations) (a). The XRD pattern of pure struvite and recovery struvite (b). The red line represents pure struvite, and the black line represents collected struvite

detained by the membrane, the volatile organic compounds, such as volatile fatty acid, which exert partial pressures comparable to or higher than those exerted by water, were transported across the membrane $[4,18]$. This resulted in the condensed water containing $120-200 \mathrm{mg} \mathrm{L}^{-1}$ of COD.

The $\mathrm{pH}$ of the leachate was 7.62 , when the MFC was operated in the open-circuit mode, the $\mathrm{pH}$ of the recovery water was approximately the same as that of the MFC medium at 8.5; but the $\mathrm{pH}$ was 9.2 for the recovery water in the closed-circuit mode, both for mesophilic or thermo-MFCs. Gajda et al. [15] used a 20-mM sodium acetate medium in their MFCs and determined the $\mathrm{pH}$ of the collected catholyte samples to be in the range 10.6-12.7, suggesting the presence of high caustic content. In this study, high-ammonia wastewater was treated. It is assumed that when the ionic ammonium transfers to volatile ammonia, the $\mathrm{NH}_{4}{ }^{+} / \mathrm{NH}_{3}$ couple has a pKa of approximately 9.2, which suggests that the local cathode $\mathrm{pH}$ in MFCs can be maintained at approximately this $\mathrm{pH}$ value [19]. Thus, the $\mathrm{pH}$ of the cathode remains at approximately 9.2 because of the $\mathrm{NH}_{4}{ }^{+} / \mathrm{NH}_{3}$ couple, which acts as a buffer to reduce the cathode overpotential and to increase the power of the MFCs.

\section{MFC restoration from inhibition of high strength of ammonia wastewater}

Leachate recirculation is a commonly used method to enhance mass transfer in solid-state anaerobic fermentation by 


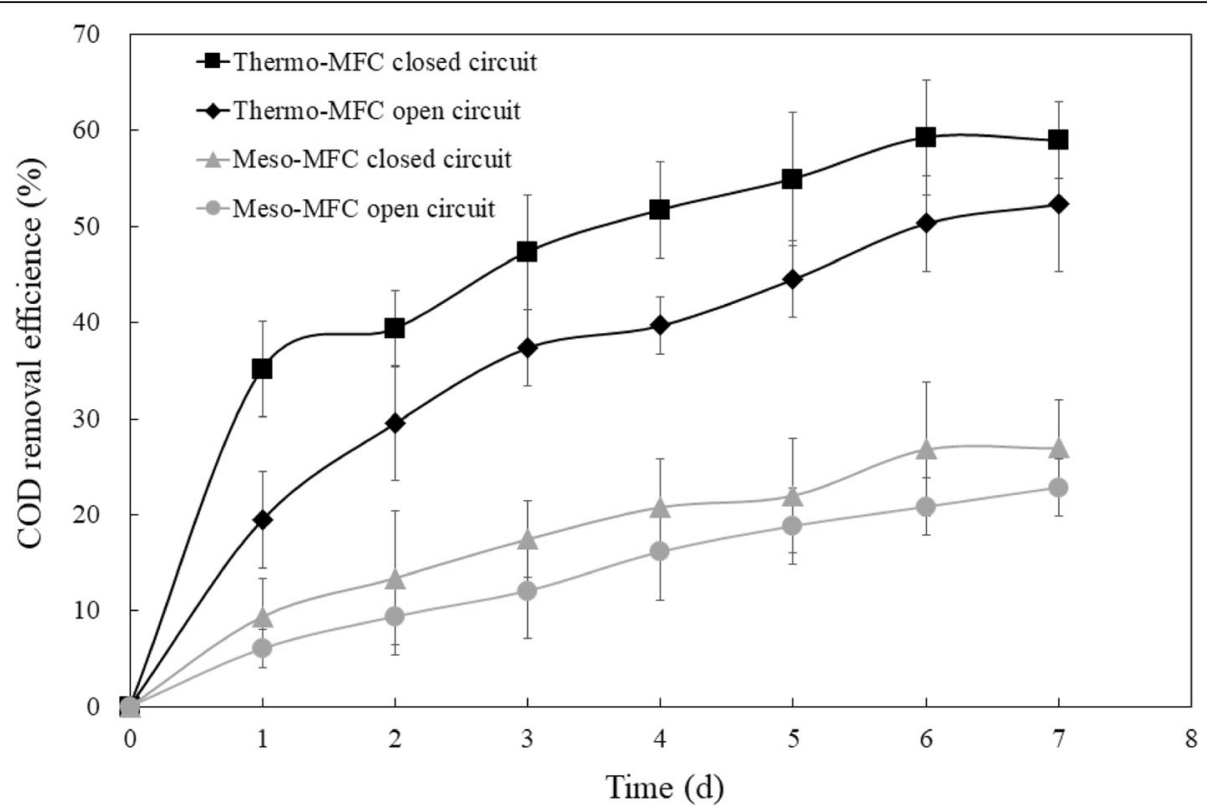

Fig. 4 COD removal using the thermo-MFC and meso-MFC (bars indicate the standard deviations). The high temperature and closed-circuit mode promote better performance in the biological treatment process

redistributing substrates, nutrients, and microorganisms [20]. However, the concentrations of ammonia and COD in the leachate increase rapidly during the first few days of hydrolysis of the organic, protein, and urea, which inhibits the system operation. From the previously conducted test in this study, it was observed that the proposed air-cathode singlechamber MFC can reduce ammonia concentration by diffusion through membrane, irrespective of whether it is operated in a closed- or open-circuit mode. However, with an electrochemical reaction, a closed-circuit MFC can induce ammonium ion migration and high $\mathrm{pH}$ adjacent to cathode to increase ammonia removal efficiency. In this study, leachate with high-strength ammonia and COD was tested on both meso-MFC and thermo-MFC to verify their restoration

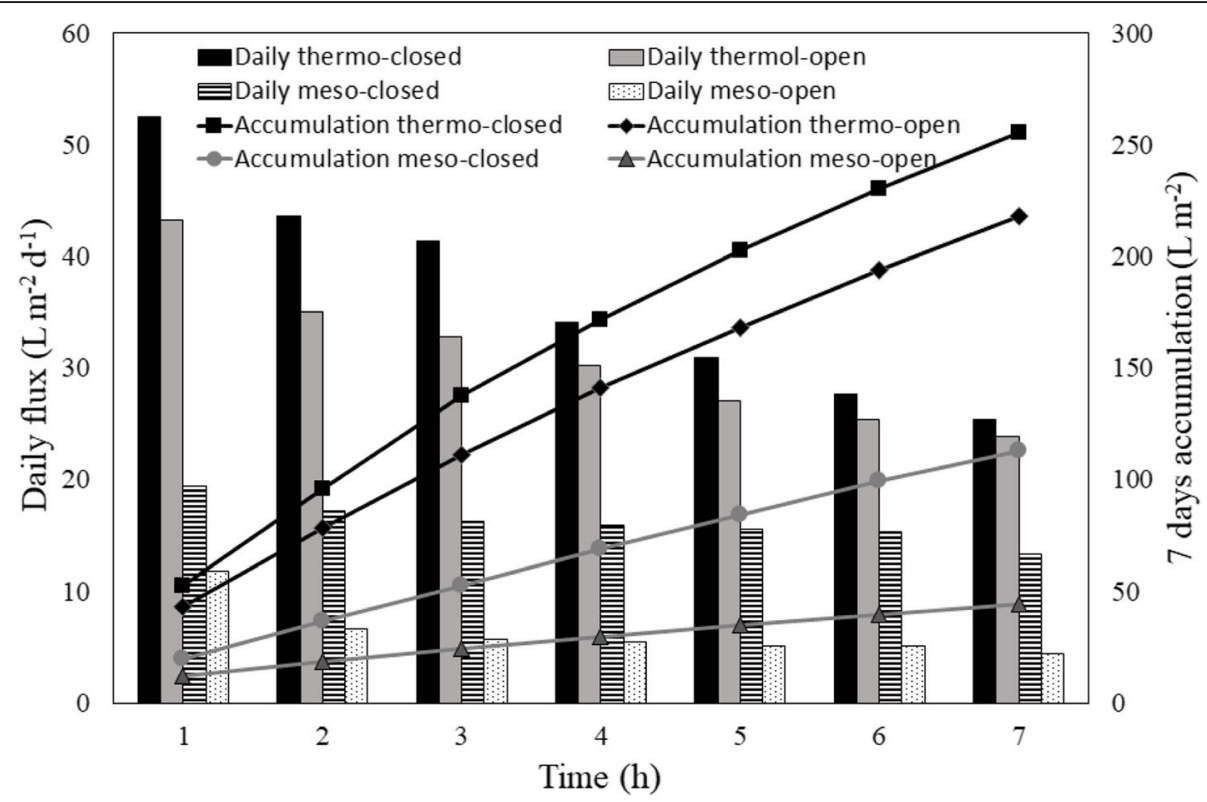

Fig. 5 Accumulation and daily water flux of the thermo-MFC and meso-MFC using open- or closed-circuit modes. The average water fluxes are 36.5 and $31.1 \mathrm{~L} \mathrm{~m}^{-2} \mathrm{~d}^{-1}$ ) for the closed- and open-circuit thermo-MFCs, which are higher than 16.2 and $6.3 \mathrm{~L} \mathrm{~m}^{-2} \mathrm{~d}^{-1}$ for the closed- and opencircuit meso-MFCs, respectively 


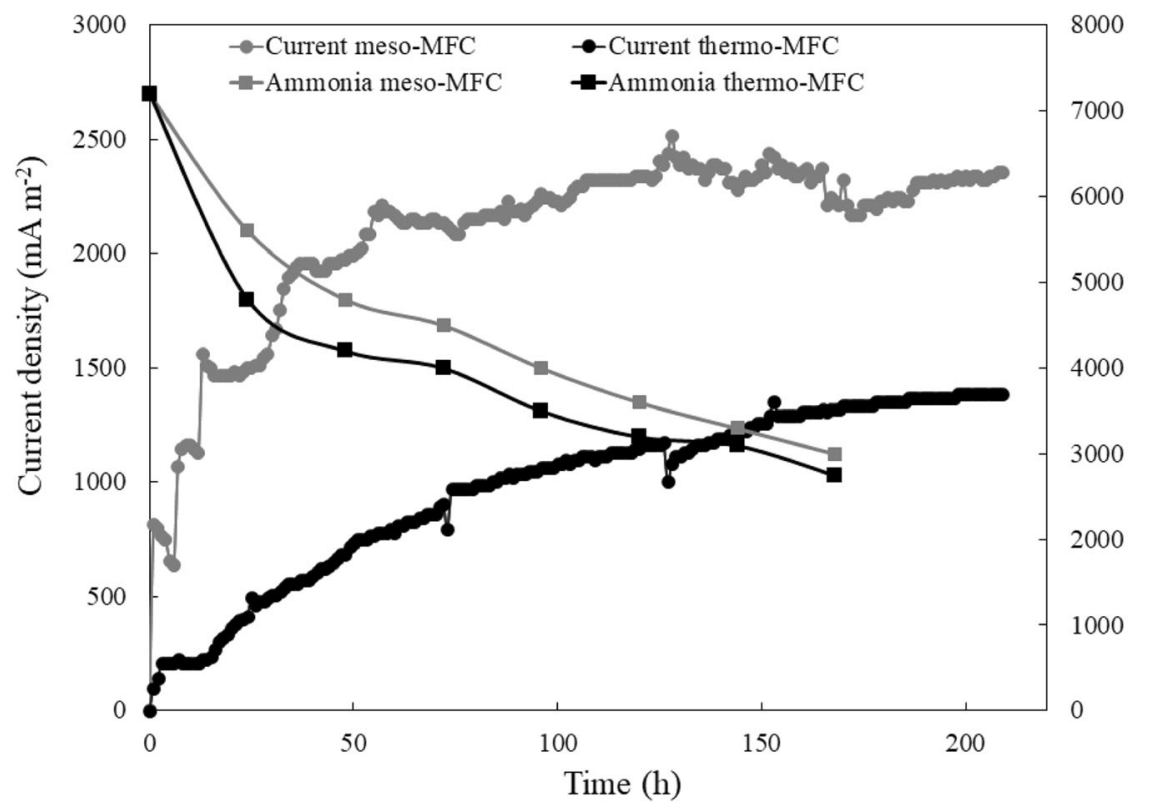

Fig. 6 Current density and ammonia concentration of the thermo- and meso-MFC with high strength of organic and ammonia in leachate B. The ammonia toxicity is alleviated as ammonia concentration gradually decreased, and as a result, the current generation is restored and increases

capability from ammonia inhibition. The leachate came from thermophilic solid-state anaerobic fermentation system for treatment of chicken manure directly at the 3rd day of operation. Although it contained high ammonia $7200 \pm 100 \mathrm{mg} \mathrm{L}^{-1}$, but it was at the initial hydrolysis and acetogenisis periods, the relative high concentration of volatile fatty acid (acetic acids, propionic acid and butyric acid, glucose) in the leachate (B) had a pH of 6.5 as well as $36,700 \pm 600 \mathrm{mg} \mathrm{L}^{-1}$ of COD.

Figure 6 presents the current density and ammonia reduction after the high-strength leachate B was fed in the MFCs. For both meso-MFC and thermo-MFC, there is a time lag of $20 \mathrm{~h}$ for high-strength ammonia, but after $24 \mathrm{~h}$, the ammonia concentration reduces from 7200 to $4800 \mathrm{mg} \mathrm{L}^{-1}$ (loss of $33 \%$ for thermo-MFC) and $5600 \mathrm{mg} \mathrm{L}^{-1}$ (loss of $22 \%$ for meso-MFC), respectively. Ammonia toxicity is alleviated as ammonia concentration decreases gradually, and as a result, current generation is restored and increases gradually. When ammonia concentration reduced to $4000 \mathrm{mg} \mathrm{L}^{-1}$ (3rd day), current density in meso-MFC increased and reached a plateau at approximately $2300 \mathrm{~mA} \mathrm{~m}^{-2}$; in thermo-MFC, it increased, reached a plateau at $1200 \mathrm{~mA} \mathrm{~m}^{-2}$, and gradually increased to $1500 \mathrm{~mA} \mathrm{~m}^{-2}$ after $7 \mathrm{~d}$. The current density was higher than that in the previous test $(1900$ vs. $875 \mathrm{~mA}$ $\mathrm{m}^{-2}$ ). Substrates with high COD concentration and more microorganisms acclimated with high-ammonia strength are presumed to exhibit high current density. A thermophilic anaerobic system easily experiences ammonia inhibition, but the proposed thermophilic single-chamber air-cathode MFC can alleviate ammonia inhibition by diffusing the volatile ammonia from the air cathode.

\section{Conclusions}

Increased process temperature positively affects the metabolic rate of microorganisms, but it also results in inhibition because of a high concentration of free ammonia. However, in our study, the thermo-MFCs exhibit higher ammonia removal rate than the meso-MFCs do, and the proposed method requires neither reduction of temperature nor addition of $\mathrm{NaOH}$. The single-chamber air-cathode MFC presents an economic and ecofriendly system, but further study is necessary to achieve a better configuration to reduce the sweeping air.

\section{Acknowledgements}

The authors acknowledge the financial support (grant numbers 108-D0109) provided by the Bureau of Energy, MOEA, Taiwan, ROC.

\section{Authors' contributions}

K-TC and M-DB conceived and planned the experiment. H-YY and Y-CC carried out the struvite experiment. W-JL supervised the project. K-TC wrote the manuscript with the consultation with $\mathrm{CH}$. All authors read and approved the final manuscript.

\section{Funding}

This work was supported by the Bureau of Energy, MOEA, Taiwan, ROC (grant number 108-D0109).

\section{Availability of data and materials}

The data used to support the findings of this study are available from the corresponding author upon request.

\section{Competing interests}

The authors declare that they have no competing interests.

\section{Author details}

${ }^{1}$ Green Energy and Environment Research Laboratories, Industrial Technology Research Institute, Hsinchu 31057, Taiwan. ${ }^{2}$ Institute of Environmental Engineering, National Chiao Tung University, Hsinchu 30010, Taiwan. 
Received: 29 August 2019 Accepted: 9 January 2020

Published online: 23 January 2020

\section{References}

1. Chen Y, Cheng JJ, Creamer KS. Inhibition of anaerobic digestion process: a review. Bioresour Technol. 2008;99:4044-64.

2. Hellinga C, van Loosdrecht MCM, Heijnen JJ. Model based design of a novel process for nitrogen removal from concentrated flows. Math Comp Model Dyn. 1999:5:351-71.

3. Doyle JD, Parsons SA. Struvite formation, control and recovery. Water Res. 2002;36:3925-40.

4. Xie M, Shon HK, Gray SR, Elimelech M. Membrane-based processes for wastewater nutrient recovery: technology, challenges, and future direction. Water Res. 2016;89:210-21.

5. Kuntke $P$, Smiech KM, Bruning H, Zeeman G, Saakes M, Sleutels THJA, et al. Ammonium recovery and energy production from urine by a microbial fuel cell. Water Res. 2012;46:2627-36.

6. Kuntke P, Geleji M, Bruning H, Zeeman G, Hamelers HVM, Buisman CJN. Effects of ammonium concentration and charge exchange on ammonium recovery from high strength wastewater using a microbial fuel cell. Bioresour Technol. 2011;102:4376-82.

7. Liu H, Logan BE. Electricity generation using an air-cathode single chamber microbial fuel cell in the presence and absence of a proton exchange membrane. Environ Sci Technol. 2004;38:4040-6.

8. Kuntke P, Sleutels THJA, Arredondo MR, Georg S, Barbosa SG, ter Heijne A, et al. (bio) electrochemical ammonia recovery: progress and perspectives. Appl Microbiol Biot. 2018;102:3865-78.

9. Rothrock MJ, Szogi AA, Vanotti MB. Recovery of ammonia from poultry litter using flat gas permeable membranes. Waste Manag. 2013;33:1531-8.

10. Garcia-Gonzalez MC, Vanotti MB. Recovery of ammonia from swine manure using gas-permeable membranes: effect of waste strength and $\mathrm{pH}$. Waste Manag. 2015;38:455-61.

11. Dessi P, Porca E, Haavisto J, Lakaniemi AM, Collins G, Lens PNL. Composition and role of the attached and planktonic microbial communities in mesophilic and thermophilic xylose-fed microbial fuel cells. RSC Adv. 2018;8:3069-80.

12. Li LH, Sun YM, Yuan ZH, Kong XY, Li Y. Effect of temperature change on power generation of microbial fuel cell. Environ Technol. 2013;34:1929-34.

13. Kim J, Kim K, Ye H, Lee E, Shin C, McCarty PL, Bae J. Anaerobic fluidized bed membrane bioreactor for wastewater treatment. Environ Sci Technol. 2011;45:576-81.

14. Santoro C, leropoulos I, Greenman J, Cristiani P, Vadas T, Mackay A, et al. Power generation and contaminant removal in single chamber microbial fuel cells (SCMFCS) treating human urine. Int J Hydrogen Energ. 2013;38:11543-51.

15. Gajda I, Greenman J, Melhuish C, Santoro C, Li B, Cristiani P, et al. Water formation at the cathode and sodium recovery using microbial fuel cells (MFCs). Sustain Energy Technol Assess. 2014;7:187-94.

16. Zhuang L, Zhou SG, Wang YQ, Liu CS, Geng S. Membrane-less cloth cathode assembly (CCA) for scalable microbial fuel cells. Biosens Bioelectron. 2009;24:3652-6.

17. Gajda I, Greenman J, Melhuish C, Santoro C, Li BK, Cristiani P, et al. Electroosmotic-based catholyte production by microbial fuel cells for carbon capture. Water Res. 2015;86:108-15.

18. Aydin S, Yesil H, Tugtas AE. Recovery of mixed volatile fatty acids from anaerobically fermented organic wastes by vapor permeation membrane contactors. Bioresour Technol. 2018;250:548-55.

19. Popat SC, Ki D, Young MN, Rittmann BE, Torres $\mathrm{Cl}$. Buffer $\mathrm{pK}$ a and transport govern the concentration overpotential in electrochemical oxygen reduction at neutral pH. ChemElectroChem. 2014;1:1909-15.

20. Ge XM, Xu FQ, Li YB. Solid-state anaerobic digestion of lignocellulosic biomass: recent progress and perspectives. Bioresour Technol. 2016;205:239-49.

\section{Publisher's Note}

Springer Nature remains neutral with regard to jurisdictional claims in published maps and institutional affiliations.

Ready to submit your research? Choose BMC and benefit from:

- fast, convenient online submission

- thorough peer review by experienced researchers in your field

- rapid publication on acceptance

- support for research data, including large and complex data types

- gold Open Access which fosters wider collaboration and increased citations

- maximum visibility for your research: over $100 \mathrm{M}$ website views per year

At $\mathrm{BMC}$, research is always in progress.

Learn more biomedcentral.com/submissions 